\title{
Lipídeo e vitamina C em dietas preparatórias de inverno para tilápias-do-nilo
}

\author{
Dario Rocha Falcon², Margarida Maria Barros³, Luiz Edivaldo Pezzato³, Juliana de \\ Barros Valle ${ }^{4}$
}

\author{
${ }^{1}$ Parte da dissertação de Mestrado apresentada ao Programa de Pós-graduação em Zootecnia da FMVZ, UNESP, Campus de Botucatu, \\ SP, pelo primeiro autor. Apoio: FAPESP (01/11237-4). \\ 2 Unesp - Universidade Estadual Paulista, AquaNutri - FMVZ, Campus de Botucatu, SP. \\ ${ }^{3}$ Departamento de Melhoramento e Nutrição Animal - AquaNutri, FMVZ, Unesp, Campus de Botucatu, SP. \\ 4 Incaper, Aqüicultura e Pesca, ES.
}

RESUMO - Foram avaliados o desempenho produtivo e os parâmetros fisiológicos de tilápias-do-nilo alimentadas, durante 112 dias, com dietas preparatórias para o inverno, formuladas com diferentes níveis de lipídeo e vitamina C. Utilizaram-se 192 alevinos $(5,57 \pm 0,50 \mathrm{~g})$ distribuídos em 32 tanques-rede. O experimento foi conduzido em esquema fatorial $2 \times 3$, composto de dois níveis (8,0 e 12,0\%) de lipídeo e três níveis (300,0; 600,0 e 1.200,0 mg/kg de ração) de vitamina C, em comparação a duas dietas (uma isenta dos nutrientes-teste e outra com 6,0\% de lipídeo e 125,0 mg de vitamina C), totalizando oito dietas isoprotéicas (32,0\% de proteína digestível). A energia adicional proveniente do lipídeo é depositada na cavidade abdominal em forma de gordura visceral; a deposição desta gordura como reserva de energia foi obtida nos níveis de suplementação de lipídeo testados; a concentração hepática de vitamina C é proporcional à sua concentração na dieta; a ausência desta vitamina na dieta prejudica a eritropoiese e a síntese de colágeno.

Palavras-chave: ácido ascórbico, estresse ao frio, exigência nutricional, lipídeo, tilápia-do-nilo

\section{Lipid and vitamin C in practical diets preparatory for winter for Nile tilapia}

\begin{abstract}
In order to prepare tilapia for winter, it were evaluated the effect of two levels of lipid (8.0 and $12.0 \%)$ and three levels of vitamin C (300.0; 600.0 and 1,200.0 $\mathrm{mg}$ of vitamin C/kg diet), with four replicates each treatment, plus two treatments, absent of test nutrients supplementation and supplemented with $6.0 \%$ of lipid and $125.0 \mathrm{mg}$ of vitamin $\mathrm{C} / \mathrm{kg}$ diet on growth performance and physiologic parameters during 112 days. It was utilized 192 fingerlings, with average weight of $5.57 \pm 0.50 \mathrm{~g}$. Based on the results it was concluded that the additional energy coming from lipid is accumulated in abdominal cavity; fat deposition as a energy reserve for winter time was obtained in all lipid supplementation, however $8.0 \%$ supplementation seems to be more appropriate; the concentration of $600.0 \mathrm{mg}$ of vitamin $\mathrm{C} / \mathrm{kg}$ diet appears to be more economically appropriate and that vitamin C absence impairs erythropoiesis and collagen syntheses.
\end{abstract}

Key Words: ascorbic acid, lipid, Nile tilapia, requirement, temperature stress

\section{Introdução}

Nas últimas décadas, o sistema intensivo foi a técnica de criação mais difundida e adotada por criadores de peixes. Neste sistema, os peixes são expostos a diversos agentes estressores, que podem ocasionar alterações prejudiciais na sua condição fisiológica. Muitos agentes estão relacionados às características físico-químicas da água, como, por exemplo, a temperatura, que pode sofrer alterações abruptas, principalmente durante o inverno, e diminuir a resistência orgânica dos peixes.

O estado nutricional do animal, por ser conseqüência direta e indireta da quantidade e qualidade dos nutrientes disponíveis na dieta, pode ser positivamente alterado. Desse modo, em virtude da ampla participação metabólica, vários aspectos da dieta podem preparar o peixe para situações adversas. A vitamina C, os lipídeos e seus constituintes, ácidos graxos, exercem em peixes funções essenciais e dinâmicas na manutenção do crescimento, da higidez, da eficiência alimentar, da reprodução e da qualidade de filé (Balfry \& Higgs, citados por Lim \& Webster, 2001) e, conseqüentemente, favorece o equilíbrio orgânico.

Os lipídeos são o depósito primário de energia, acumulada em forma de triacilglicerol para ser utilizada em situações desfavoráveis (Stickney, 1997, citado por Costa-Pierce \& Rakocy, 1997). Perda de peso no inverno em razão da pequena reserva lipídica foi observada em bagre-do-canal (Ictalurus punctatus) por Lovell \& Sirikul (1974). Resultado 
semelhante foi relatado por Lemly (1996), que observou durante o inverno queima acelerada e esgotamento das reservas lipídicas, comprovando a necessidade de adequada reserva para não deteriorar as condições corporais dos peixes.

A deficiência na capacidade de síntese de vitamina C pelos peixes, em virtude da ausência da enzima Lgulonolactona oxidase, determina a necessidade de suplementação, em quantidades adequadas, desta vitamina na dieta para suprir as necessidades metabólicas da espécie (Lovell, 1998). A vitamina C participa da síntese de colágeno, conferindo maior resistência à fibra, do metabolismo do ferro, transformando-o do estado férrico para o estado ferroso, e da síntese de carnitina a partir da lisina e metionina. Atua ainda na conversão do ácido fólico para folínico e pode minimizar a ação de radicais livres, evitando a desestabilização da membrana lipídica (Lehninger et al., 1995; Chien \& Hwang, 2001).

Alterações metabólicas durante situações desfavoráveis geram redistribuição e maior demanda por vitaminas, especialmente a vitamina C (Wedemeyer, 1969). Recomenda-se suplementação em níveis superiores ao necessário para proporcionar aos peixes desempenho normal visando maior resistência a doenças (Li \& Lovell, 1985). Peixes com alta concentração de ácido ascórbico nos tecidos apresentam maior tolerância à poluição ambiental e maior resistência a infecções por bactérias (Navarre \& Halver, 1989). Sobhana et al. (2002) demonstraram que a suplementação de vitamina $\mathrm{C}$ em níveis elevados aumentou significativamente a sobrevivência, a atividade fagocítica e a resistência contra Aeromonas hydrophila em carpa indiana (Cirrhinus mrigala). Igualmente, Ai et al. (2006) relataram que a mortalidade cumulativa diminuiu à medida que aumentou o nível de vitamina C na dieta de Pseudosciaena crocea desafiado com bactéria.

Considerando essas informações e a necessidade de se avaliar a correlação entre a nutrição e a saúde dos peixes, objetivou-se com esta pesquisa avaliar os efeitos de níveis de lipídeos e vitamina $C$ e de suas interações no desempenho produtivo e nos parâmetros fisiológicos de tilápias-do-nilo visando dar resistência a esses animais para o período de inverno.

\section{Material e Métodos}

A pesquisa foi realizada na Universidade Estadual Paulista - UNESP, Faculdade de Medicina Veterinária e Zootecnia, Departamento de Melhoramento e Nutrição
Animal, Laboratório de Nutrição de Organismos Aquáticos - AquaNutri, associado ao CAUNESP, durante o período de 112 dias.

Utilizou-se um lote de 192 alevinos de tilápia-do-nilo (Oreochromis niloticus) provenientes da mesma desova e revertidos sexualmente, com 5,57 $\pm 0,50 \mathrm{~g}$, distribuídos aleatoriamente em 32 tanques-rede de $200 \mathrm{~L}$ cada um, em densidade de seis peixes por tanque-rede. Foram dispostos em oito aquários de 1.000 L quatro tanques-rede por aquário. O conjunto de aquários tem sistema de aquecimento controlado por termostato, que manteve a temperatura na faixa de conforto $\left(26,0 \pm 1,0^{\circ} \mathrm{C}\right)$, e sistema de recirculação de água, com filtragem mecânica e biológica. Semanalmente, foram verificadas as características físico-químicas da água dos aquários e realizada sifonagem para retirada de eventuais resíduos orgânicos.

O experimento foi realizado em esquema fatorial $2 \times 3$, com dois níveis de lipídeo (8,0 e 12,0\% da dieta) e três níveis de vitamina C (300,0; 600,0 e 1.200,0 mg por kg da dieta), com quatro repetições para cada nível. As dietas experimentais foram comparadas a outras duas: uma ausente dos nutrientes-teste, e outra acrescida de 6,0\% de lipídeo e 125,0 mg de vitamina C/kg, valores comumente utilizados pelas indústrias de rações para peixes. Portanto, foram confeccionadas oito rações práticas, isoprotéicas, com 32,0\% de proteína digestível (Tabela 1). Como fonte de lipídeo, utilizou-se óleo de soja comercial. A vitamina C utilizada foi a polifosfatada com $35,0 \%$ de atividade (Stay$\mathrm{C}^{\circledR}$ Roche). O suplemento vitamínico e mineral empregado era isento de vitamina $\mathrm{C}$ e, por isso, foi considerado fonte somente o produto adicionado à dieta.

As dietas foram peletizadas e, posteriormente, fracionadas em diferentes diâmetros, adequados ao tamanho dos peixes. As dietas foram armazenadas em congelador $\left(-20^{\circ} \mathrm{C}\right)$ para evitar perdas de vitamina $\mathrm{C}$ pelo processo de oxidação. A dieta acondicionada em potes individuais para alimentação diária foi conservada em refrigerador $\left(3^{\circ} \mathrm{C}\right)$ em quantidade equivalente a uma semana de alimentação. As dietas foram ministradas diariamente nos horários de 8h30, $11 \mathrm{~h} 30,14 \mathrm{~h} 30$ e $17 \mathrm{~h} 30$ e, durante o arraçoamento, foram ofertadas de duas a três vezes na tentativa de se alcançar a saciedade dos peixes.

Ao final de 112 dias, foram determinados o ganho de peso, a conversão alimentar aparente e o consumo aparente de ração. Os peixes foram pesados individualmente e o consumo aparente da dieta foi quantificado. Durante a pesagem, realizou-se a análise macroscópica dos peixes para determinação de possíveis sinais clínicos de deficiência de vitamina C. 
Tabela 1 - Composições percentual e químico-bromatológica das dietas experimentais e composição químico-bromatológica da carcaça dos peixes ao final do período experimental

Table 1 - Percentage and chemical compositions of the experimental diets and chemical composition of carcass at the end of experimental period

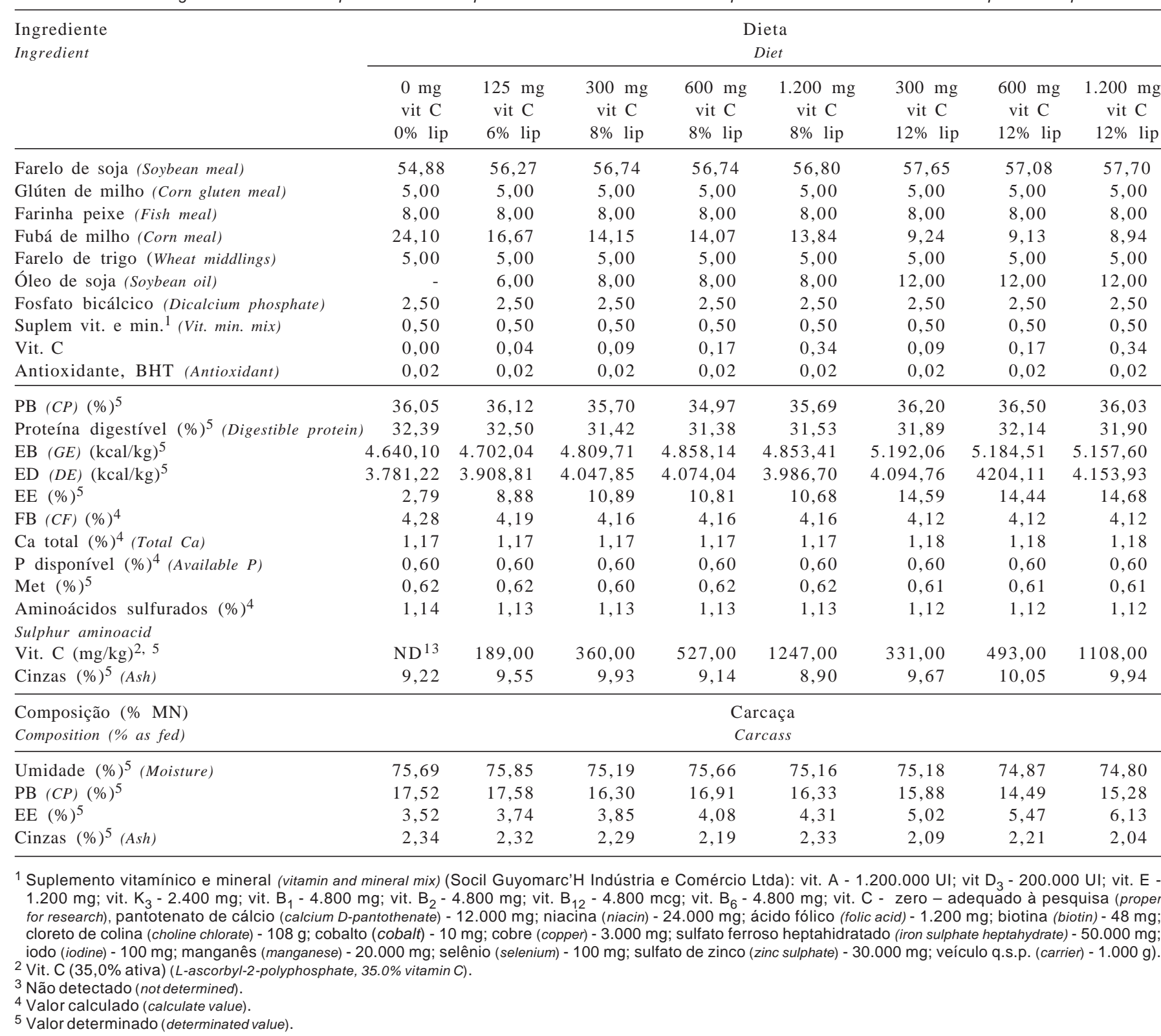

Para determinação da gordura visceral, foram avaliados cinco peixes por tratamento, os quais foram sacrificados utilizando-se superdosagem do anestésico benzocaína (etil para-aminobenzoato - $\mathrm{C}_{9} \mathrm{H}_{11} \mathrm{NO}_{2}$ - U.S.P. Synth). Efetuaram-se três incisões dorsoventrais nos peixes (uma próxima ao opérculo, outra na abertura do poro urogenital e a outra paralela ao dorso, na região abdominal ventral) para melhor exposição dos órgãos cavitários. Após a quantificação da gordura, foi calculado o índice de gordura visceral IGV = [(peso gordura $(\mathrm{g}) /$ peso corporal (g) $) \times 100]$.

Desses mesmos peixes foram retirados e congelados os filés para posterior determinação da porcentagem de lipídeo
(AOAC, 2000). Foram ainda extraídos os fígados para quantificação da vitamina C. Os fígados foram imediatamente imersos em nitrogênio líquido e posteriormente armazenados em congelador a $-80^{\circ} \mathrm{C}$. A análise de vitamina $\mathrm{C}$ foi feita em cromatógrafo líquido (HPLC - fase reversa), de acordo com metodologia de Wang et al. (1988). Amostras de 1,0 a 2,0 g foram finamente moídas, extraídas em banho de ultra-som durante 15 minutos e, depois de resfriadas, foram filtradas em filtro millex $(0,45 \mathrm{~mm})$. As condições cromatográficas foram: coluna ODS (C18-150 ×4.6 mm), temperatura de $25^{\circ} \mathrm{C}$ e detector de UV $280 \mathrm{~nm}$. O nível de detecção foi de aproximadamente 10 ppm e a eficiência de recuperação de $94,0 \%$. 
Destas mesmas amostras, foi determinada também a porcentagem de extrato etéreo (AOAC, 2000) e calculado o índice hepatossomático; IHS = [(peso fígado $(\mathrm{g}) /$ peso corporal (g)) $\times 100]$.

Para quantificação da porcentagem de colágeno, as carcaças desses peixes foram fervidas em água por 10 minutos e, com auxílio de pinça e escova, foram retiradas as possíveis sobras de tecido muscular e separadas as vértebras. As vértebras foram imersas em solução de hidróxido de sódio $0,1 \mathrm{~N}$ por 24 horas e, posteriormente, foram secas por 12 horas a $55^{\circ} \mathrm{C}$ em estufa de circulação forçada, de acordo com metodologia de Mustin \& Lovell (1992).

Foram também efetuadas radiografias de dois peixes por tratamento, no Departamento de Reprodução Animal e Radiologia Veterinária da Faculdade de Medicina Veterinária e Zootecnia, Campus de Botucatu, para verificar possíveis deformidades.

A determinação dos parâmetros hematológicos foi realizada em cinco peixes por tratamento, capturados aleatoriamente. Os peixes foram anestesiados com benzocaína ( $1,0 \mathrm{~g} / 15 \mathrm{~L})$ e o sangue foi coletado com auxílio de seringa de $1,0 \mathrm{~mL}$, banhada com anticoagulante $(0,2 \mathrm{~mL}$ de EDTA sal dipotássio PA 2-hidratado 3,0\%), através do vaso caudal. A contagem de eritrócitos foi realizada em hemocitômetro (1:200) utilizando-se como corante solução de azul de toluidina a $0,01 \%$. A taxa de hemoglobina foi determinada pelo método da cianometahemoglobina utilizando-se kit comercial (Analisa Diagnostica ${ }^{\circledR}$ ) para determinação colorimétrica. A contagem de eritrócitos e a taxa de hemoglobina foram avaliadas utilizando-se as técnicas descritas por Jain (1986). A porcentagem de hematócrito foi obtida pelo método do microhematócrito (5.000 rpm/5 minutos). Posteriormente a essas análises, foram calculados os índices hematimétricos, o volume corpuscular médio (VCM) e a concentração de hemoglobina corpuscular média (CHCM).

Ao final do período experimental, foram efetuadas análises químico-bromatológicas das dietas experimentais e das carcaças dos peixes determinando-se as porcentagens de matéria seca, proteína bruta, extrato etéreo e cinzas, segundo AOAC (2000). Foi determinada ainda a quantidade de vitamina C em cromatógrafo líquido (HPLC) das diferentes dietas experimentais. Para determinação do coeficiente de digestibilidade aparente das dietas, foi acrescido às dietas $0,1 \%$ de óxido de cromo III $\left(\mathrm{Cr}_{2} \mathrm{O}_{3}\right)$, segundo metodologia relatada por Granner (1972), conforme protocolo descrito por Pezzato et al. (2002), com duração de 15 dias (Tabela 1).

A análise estatística foi realizada por meio da técnica da ANOVA para o esquema fatorial $2 \times 3$, com dois tratamentos adicionais no delineamento inteiramente casualizado, complementado com os testes de Scheffé e Tukey (estrutura fatorial) (Yassin, 2001).

\section{Resultados e Discussão}

No decorrer do período experimental, a temperatura da água dos aquários oscilou, com média de $26,0 \pm 1,0^{\circ} \mathrm{C}$. Onível de oxigênio dissolvido foi 7,5 $\pm 0,5 \mathrm{mg} / \mathrm{L} \mathrm{e} \mathrm{opH,} 7,0 \pm 0,5$. Estes valores se enquadram na faixa ótima para o desenvolvimento da espécie, segundo Boyd (1990), e, portanto, não influenciaram os parâmetros avaliados.

Quando os resultados obtidos com a dieta sem suplementação foram comparados à média obtida com as dietas suplementadas (fatorial), observou-se efeito $(\mathrm{P}<0,05)$ da suplementação de lipídeos e vitamina $\mathrm{C}$ no ganho de peso (Tabela 2). Aplicando-se o índice relativo de comparação (IRC) e considerando o tratamento sem suplementação como $100 \%$, verificou-se ganho médio de peso dos demais tratamentos em $17,8 \%$. Resultados similares foram relatados por Chagas \& Val (2003).

Embora o efeito dos níveis de lipídeo (Tabela 2) não tenha sido significativo, o nível de $12,0 \%$ de suplementação resultou em aumento de 3,2\% no ganho de peso em comparação ao nível de 8,0\% de lipídeo. Respostas semelhantes foram obtidas por Hanley (1991) em tilápias-do-nilo e por Chou \& Shiau (1996) em híbridos de tilápia (Oreochromis niloticus x Oreochromis aureus). Entretanto, resultados contrários de ganho de peso foram descritos por Jauncey \& Ross (1982), que relataram que tilápias não toleram altos níveis de lipídeo como os salmonídeos e podem apresentar supressão dos parâmetros produtivos quando alimentadas com dietas suplementadas com níveis superiores a 12,0\%. Similarmente, o aumento dos níveis de lipídeo em dietas para alevinos de carpa-capim (Ctenopharyngodon idella) e de tilápia-do-nilo apresentou redução linear no ganho de peso (Hayashi et al., 1999; Meurer et al., 2002).

Não houve efeito significativo da suplementação de lipídeos e vitamina $\mathrm{C}$ sobre o consumo aparente da dieta (Tabela 2). No entanto, houve tendência de redução no consumo com o aumento de 8,0 para $12,0 \%$ na porcentagem de lipídeo na dieta, demonstrando coerência com a quantidade de energia digestível das dietas (Tabela 1). Embora a presença de lipídeo melhore a palatabilidade, a quantidade de energia digestível pode ter influenciado a ingestão da dieta, resultado sugerido também por De Silva et al. (1991).

A conversão alimentar aparente (Tabela 2) sofreu efeito significativo da dieta sem suplementação e da dieta suplementada com 6,0\% de lipídeos e 125,0 mg vitamina C/kg 
Tabela 2 - Valores médios de ganho de peso por peixe (GPP), consumo aparente da ração, conversão alimentar aparente (CAA), gordura visceral (GV) e índice de gordura visceral (IGV) de alevinos de tilápia do Nilo arraçoados com dietas suplementadas em níveis de lipídeo e vitamina $C$ durante 112 dias $^{1}$

Table 2 - Mean values of growth performance (GP), apparent diet consumption (ADC), apparent feed conversion (AFC), visceral fat (VF) and visceral fat index (VFI) of Nile tilapia juveniles fed diets supplemented with different levels of vitamin C and lipids during 112 days

\begin{tabular}{|c|c|c|c|c|c|c|}
\hline Vit C (mg/kg) & Lip (\%) & $\begin{array}{c}\text { GPP (g) } \\
\quad G P\end{array}$ & $\begin{array}{l}\text { Consumo (g) } \\
\text { Consumption }\end{array}$ & $\begin{array}{l}\text { CAA } \\
\text { AFC }\end{array}$ & $\begin{array}{l}\text { GV (g) } \\
\quad V F\end{array}$ & $\begin{array}{l}\text { IGV } \\
\text { VFI }\end{array}$ \\
\hline 0 & 0 & $86,06( \pm 10,05)$ & $117,37( \pm 4,28)$ & $1,37( \pm 0,05)$ & $0,43( \pm 0,36)$ & $0,42( \pm 0,22)$ \\
\hline 125 & 6 & $96,29( \pm 33,19)$ & $120,80( \pm 4,60)$ & $1,27( \pm 0,03)$ & $1,71( \pm 0,54)$ & $1,29( \pm 0,22)$ \\
\hline$\overline{300}$ & & $92,63( \pm 31,43)$ & $112,86( \pm 7,25)$ & $1,22 \mathrm{~B}( \pm 0,07)$ & $\overline{1,73( \pm 0,26)}$ & 1,23 В $( \pm 0,23)$ \\
\hline 600 & 8 & $104,99( \pm 37,99)$ & $119,70( \pm 4,33)$ & $1,14 \mathrm{~B}( \pm 0,03)$ & $1,86( \pm 0,68)$ & 1,55 В $( \pm 0,21)$ \\
\hline 1.200 & & $101,70( \pm 49,40)$ & $118,47( \pm 5,06)$ & 1,17 B $( \pm 0,02)$ & $2,02( \pm 1,49)$ & 1,46 В $( \pm 0,35)$ \\
\hline 300 & & $103,09( \pm 47,73)$ & $113,94( \pm 8,16)$ & 1,06 A $( \pm 0,03)$ & $2,75( \pm 1,90)$ & 2,01 A $( \pm 0,37)$ \\
\hline 600 & 12 & $104,65( \pm 34,13)$ & $113,53( \pm 4,54)$ & 1,09 A $( \pm 0,04)$ & $2,70( \pm 1,71)$ & 1,97 A $( \pm 0,35)$ \\
\hline 1.200 & & $101,04( \pm 33,35)$ & $112,10( \pm 4,34)$ & 1,11 A $( \pm 0,05)$ & $2,89( \pm 1,10)$ & 2,10 A $( \pm 0,37)$ \\
\hline \multicolumn{2}{|c|}{$\begin{array}{l}\text { Controle. } 1 \times \text { fatorial }^{2} \\
\text { Control } 1 \times \text { factorial }\end{array}$} & 0,05 & ns & 0,01 & 0,01 & 0,01 \\
\hline \multicolumn{2}{|c|}{$\begin{array}{l}\text { Controle } 2 \times \text { Fatorial }^{3} \\
\text { Control } 2 \times \text { factorial }\end{array}$} & ns & ns & 0,05 & 0,05 & 0,05 \\
\hline \multicolumn{2}{|l|}{ Vit $C^{4}$} & ns & ns & ns & ns & ns \\
\hline \multirow{6}{*}{$\begin{array}{c}300 \\
600 \\
1.200 \\
\end{array}$} & & 97,86 & 113,40 & 1,14 & 2,24 & 1,62 \\
\hline & & 104,82 & 116,62 & 1,12 & 2,28 & 1,76 \\
\hline & & 101,55 & 115,29 & 1,14 & 2,46 & 1,78 \\
\hline & $\mathrm{Lip}^{5}$ & ns & ns & 0,01 & ns & 0,05 \\
\hline & 8 & 99,77 & 117,01 & 1,18 & 1,87 & 1,41 \\
\hline & 12 & 102,93 & 113,19 & 1,09 & 2,78 & 2,03 \\
\hline \multicolumn{2}{|l|}{ Vit C x Lip ${ }^{6}$} & ns & ns & ns & ns & ns \\
\hline \multicolumn{7}{|c|}{$\begin{array}{l}{ }^{1} \text { Letras minúsculas comparam os níveis de vit. C dentro de um mesmo nível de lipídeo (Small letters compare vit. Clevels within the same lipid level). Letras maiúscula } \\
\text { comparam diferentes níveis de lipídeo dentro de um mesmo nível de vit. C (Capital letters compare different lipid levels within the same vit. C level). Médias seguida } \\
\text { de letras iguais, ou sem letra, não diferem (Means followed by the same letter or absent did not differ). } \\
2 \text { Controle } 1 \text { (control 1) (ausente de suplementação de vitamina C e lipídeo) (No vitamin C and lipid supplementation) vs Fatorial, nível P (factorial, P level). } \\
3 \text { Controle } 2 \text { (control 2) (125,0 mg/kg vit. C e } 6,0 \% \text { lipídeo) (125 mg/kg vit. C) vs Fatorial, nível P (factorial, P level). } \\
4 \text { Efeito da vit. C, nível P (vit. C effect, P level). } \\
5 \text { Efeito do lipídeo, nível P (lipid effect, P level). } \\
6 \text { Interação vit. C x lipídeo, nível P (vit. C and lipid interaction, P level). }\end{array}$} \\
\hline
\end{tabular}

$(\mathrm{P}<0,05)$ em comparação à média do fatorial. Observou-se ainda efeito da suplementação de lipídeo, pois o nível de 12,0\% determinou maior nível de energia digestível e resultou em melhor conversão alimentar aparente, fato evidenciado por Beamish \& Medland (1986) em truta arco-íris (Oncorhyncus mykiss).

A análise de EE da carcaça dos peixes (Tabela 1) revelou aumento de $48,1 \%$ com a suplementação de $12,0 \%$ de lipídeo na dieta em comparação à média obtida com a dieta suplementada com 6,0\% de lipídeo e 125,0 mg de vitamina $\mathrm{C} / \mathrm{kg}$. Houve ainda aumento de $12,4 \%$ na porcentagem de extrato etéreo na carcaça dos peixes alimentados com as dietas suplementadas com 8,0\% de lipídeo em comparação à média obtida sem suplementação. O mesmo resultado foi observado Pandian \& Raghuraman (1972), que observaram níveis de 32,0 a 44,0\% em tilápia- mossambica (Oreochromis mossambicus) alimentada com dieta contendo 32,0\% de lipídeo, enquanto Hanley (1991) encon- trou níveis de 1,2\% de extrato etéreo na carcaça dos peixes da dieta sem suplementação e de 4,5 a 6,9\% nos peixes alimentados com as dietas suplementadas com 5,0 e 12,0\% de lipídeo, respectivamente.

Igualmente, Lanna et al. (2004) relataram aumento de 4,8 para 12,7\% na porcentagem de lipídeo na carcaça de tilápiado-nilo com a suplementação de $10,0 \%$ de óleo de soja na dieta. Meurer et al. (2002), para a mesma espécie, observaram aumento linear da porcentagem de gordura corporal com o acréscimo no nível de lipídeo na ração.

Para analisar a suplementação de lipídeo, no intuito de fornecer reserva de energia para transpor momentos em que a demanda energética requerida é aumentada, deve-se considerar o peso do peixe em relação à gordura depositada na cavidade visceral. Desse modo, observando-se o índice de gordura visceral (Tabela 2), notou-se efeito significativo, tanto nos peixes alimentados com a dieta sem suplementação $(\mathrm{P}<0,01)$ quanto naqueles alimentados com a dieta 
suplementada com $6,0 \%$ de lipídeo $(\mathrm{P}<0,05)$, em relação à média do fatorial. Este resultado evidencia que a suplementação de lipídeo em nível superior ao utilizado pelas indústrias de rações promoveu maior deposição de gordura.

Ressalta-se, porém, que o ganho de peso com a suplementação de 6,0\% de lipídeo (Tabela 2) não diferiu significativamente em relação ao obtido com suplementação de 8,0 e 12,0\%. A suplementação nesses níveis promoveu diferenças na conversão alimentar aparente, na gordura visceral e no índice de gordura visceral, em virtude da deposição de gordura na cavidade abdominal. Quando comparados os resultados da suplementação de 8,0 e 12,0\% de lipídeo, observou-se que suplementação no maior nível determinou aumento de $48,7 \%$ na quantidade de gordura visceral e 44,0\% no índice de gordura visceral. Esses valores determinados pela suplementação de 12,0\% de lipídeo podem ser considerados expressivos e se tornar prejudiciais em um período prolongado de utilização desta dieta.

Os resultados desta pesquisa (Tabela 2) e os descritos na literatura indicam que o peixe não aproveita toda a energia adicional proveniente do lipídeo para o crescimento e que a parcela do lipídeo que não é aproveitada para o funcionamento do metabolismo é depositada na cavidade abdominal.

Resultados semelhantes foram obtidos por Viola et al. (1980), que destacaram que a deposição de gordura com o aumento do nível de lipídeo nas dietas ocorreu mais nas vísceras e não no filé, parte comercializada do peixe. Igualmente, Fitzsimmons et al. (1997) observaram resultados similares na composição final da carcaça de híbridos de tilápia (Oreochromis niloticus $\times$ Oreochromis aureus) e ressaltaram que a não ocorrência de redução significativa dos níveis de lipídeo no filé, mesmo com o fornecimento de dieta com menor nível de suplementação, pode dificultar a comercialização deste produto em virtude da possível diminuição de sua vida útil. A composição corporal dos peixes pode ser alterada pela utilização de elevados teores de lipídios nas dietas, que influenciam as características e na conservação da carcaça e, conseqüentemente, a sua comercialização (Van der Meer et al., 1997; Rasmussen, 2001).

Os resultados obtidos nesta pesquisa (Tabela 2) mostraram que a deposição de gordura visceral para maior resistência dos peixes no período de inverno foi obtida em todos os níveis de suplementação. Todavia, em virtude das prováveis complicações fisiológicas, principalmente em decorrência da quantidade de lipídeo no fígado, e da dificuldade da tilápia-do-nilo em mobilizar elevado conteúdo de reserva lipídica, conforme apresentado na literatura, pode-se inferir que a suplementação de $8,0 \%$ proporcionou a mais adequada reserva de energia. Essa hipótese foi reforçada pela avaliação macroscópica e pela porcentagem de gordura obtidos nos peixes alimentados com a dieta suplementada com 12,0\% de lipídeo, os quais possuíam excessiva reserva de gordura visceral. Ressalta-se que não houve mortalidade em nenhum dos tratamentos testados.

Houve diferença significativa $(\mathrm{P}<0,05)$ para porcentagem de extrato etéreo no filé e no fígado, entre os resultados obtidos com as dietas sem suplementação e suplementadas com 6,0\% de lipídeo e 125,0 mg de vitamina C em relação à média do fatorial (Tabela 3). Esse efeito pode ser atribuído à suplementação de lipídeo e à energia digestível nas dietas com suplementação (fatorial). De modo semelhante, o efeito significativo $(\mathrm{P}<0,05)$ do índice hepatossomático da média das dietas suplementadas (fatorial) em relação à controle, sem suplementação, foi reflexo da alta porcentagem de extrato etéreo encontrada no fígado dos peixes. A análise macroscópica revelou alterações características de acúmulo de gordura no fígado dos peixes alimentados com as dietas suplementadas com 12,0\% de lipídeo, entre elas, coloração parda e pontos esbranquiçados (Vicentini, C.A., 2005) ${ }^{*}$.

Observou-se ainda efeito significativo $(\mathrm{P}<0,05)$ da interação vitamina $\mathrm{C} \times$ lipídeo sobre as porcentagens de extrato etéreo do filé e do fígado e aumento linear da porcentagem de extrato etéreo nos níveis de vitamina C, tanto para a suplementação com 8,0 quanto com 12,0\%. O mesmo efeito foi observado para lipídeos nos diferentes níveis de suplementação de vitamina C, comprovando efeito sinérgico desses nutrientes. Essa interação sugere que a atuação conjunta de vitamina $\mathrm{C}$ e lipídeos pode ocorrer por meio de sua ação antioxidante, que teria favorecido a manutenção da integridade do lipídeo, permitindo maior deposição (Tabela 3). Em resultados descritos na literatura, verifica-se a ação antioxidante da vitamina $\mathrm{C}$ em possibilitar economia de vitamina E, reduzindo a peroxidação do lipídeo (Lovell, 1998; Chen et al., 2004).

Os valores de eritrócitos $(\mathrm{P}<0,01)$ e a porcentagem de hematócrito $(\mathrm{P}<0,05)$ obtidos com a dieta sem suplementação diferiram significativamente da média do fatorial, no entanto, não se observou diferença significativa para a taxa de hemoglobina, o volume corpuscular médio e a concentração de hemoglobina corpuscular média. A redução do hematócrito na ausência de suplementação de vitamina C e/ou na deficiência desta vitamina foi observada em bagre-do-canal (Andrews \& Murai, 1975), truta arco-íris

* Vicentini, C.A. Informação verbal. Bauru: Departamento Ciências Biológicas, Faculdade de Ciências, Unesp, 2005. 
(Albrektsen et al., 1988), híbridos de tilápia (Shiau \& Jan, 1992) e juvenis de tambaqui, Colossoma macropomum (Chagas \& Val, 2003). No entanto, Sato et al. (1978), ao compararem a suplementação de $2.000 \mathrm{mg}$ de vitamina $\mathrm{C} / \mathrm{kg}$ da dieta à ausência desta vitamina, não notaram diferença significativa nesses parâmetros.

Os níveis de suplementação de vitamina C não influenciaram os valores hematológicos (Tabela 4), o que está de acordo com os resultados obtidos por Lim et al. (2000) e Chen et al. (2003), que não detectaram efeito significativo dos níveis de vitamina $\mathrm{C}$ na porcentagem de hematócrito. Ao contrário do observado nesta pesquisa, Barros et al. (2002) observaram influência do nível de vitamina C na porcentagem de hematócrito, que aumentou com o aumento do nível de vitamina C. Esses autores observaram, no entanto, que esse aumento foi ocasionado pelo maior volume corpuscular médio das células, demonstrando que a vitamina C determinou a liberação de células imaturas na circulação.
A deficiência de vitamina $\mathrm{C}$ pode causar anemia nos peixes, pela redução e redistribuição do íon ferro, com conseqüente diminuição da síntese de hemoglobina, e pela ocorrência de hemorragias (Albrektsen et al., 1988; Adham et al., 2000). A absorção do íon ferro no intestino e sua redistribuição para os diferentes tecidos, incluindo a síntese de hemoglobina, é facilitada pela vitamina C.

Na dieta sem suplementação de vitamina C (Tabela 4), apesar de não-significativa, a taxa de hemoglobina foi menor, o que permite inferir que os peixes alimentados com essa dieta estavam progressivamente desenvolvendo quadro anêmico. Essa hipótese pode ser reforçada pelos sinais de hemorragia apresentados pelos peixes em volta da boca e nas nadadeiras. Com a concentração de vitamina C no fígado dos peixes (Tabela 3$)$, houve efeito $(\mathrm{P}<0,05)$ da média do fatorial, em comparação à dieta sem suplementação, e efeito significativo da suplementação de vitamina C. Esse resultado comprova que a deficiência dessa vitamina não

Tabela 3 - Valores médios da porcentagem de EE no filé, no fígado, concentração de vitamina C no fígado e índice hepatossomático (IHS) de alevinos de tilápia do Nilo arraçoados com dietas suplementadas com níveis de lipídeo e vitamina C durante 112 dias ${ }^{1}$

Table 3 - Mean values of ether extract (EE) in filet, liver, vitamin c concentration in liver and hepatossomatic index (HI) of Nile tilapia juveniles fed diets supplemented with different levels of vitamin $C$ and lipids during 112 days

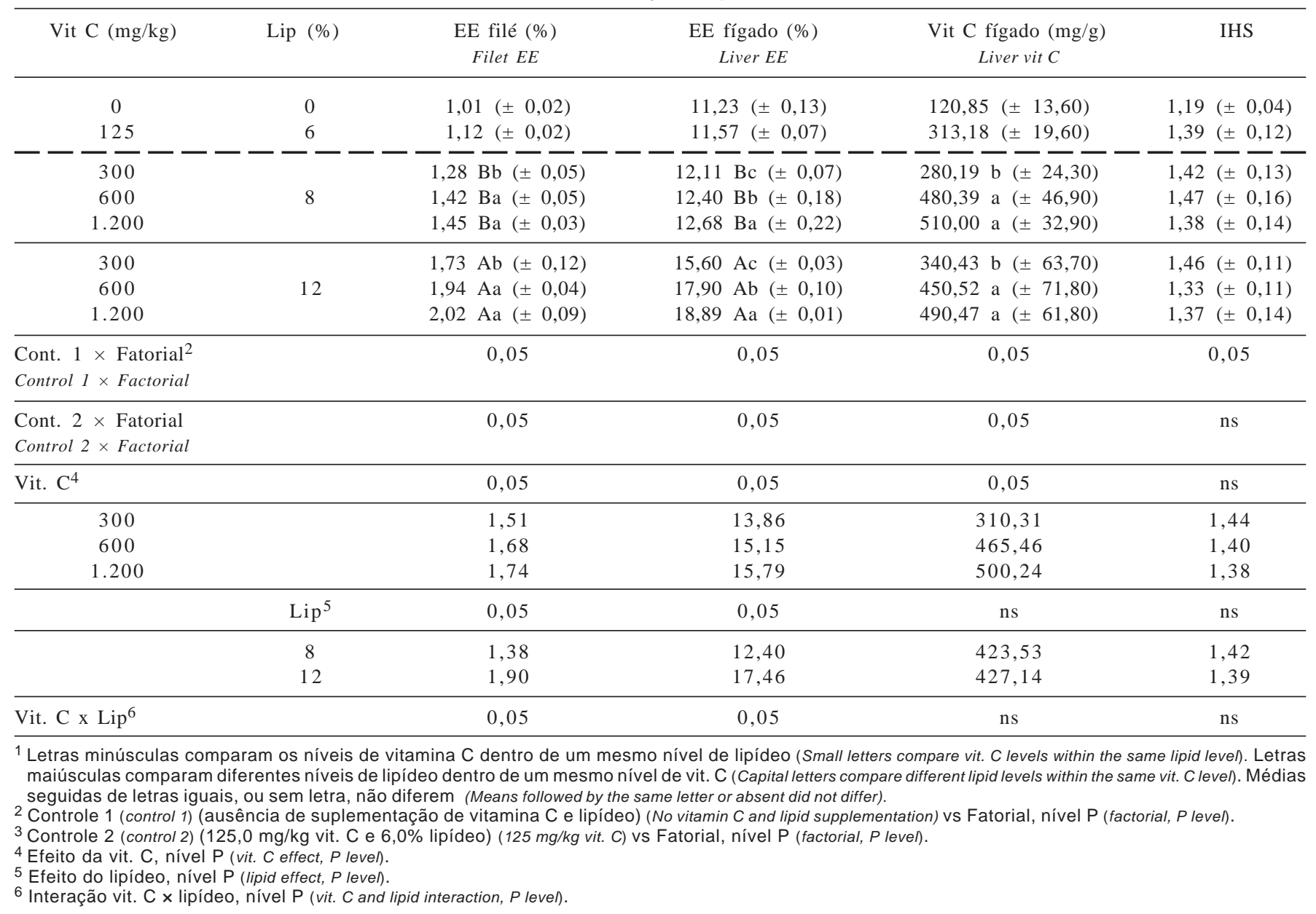


Tabela 4 - Valores médios de eritrócitos (Erit), hematócrito ( $\mathrm{Htc}$ ), hemoglobina ( $\mathrm{Hb}$ ), volume corpuscular médio (VCM) e concentração de hemoglobina corpuscular média $(\mathrm{CHCM})$ de alevinos de tilápia do Nilo arraçoados com dietas suplementadas com níveis de lipídeo e vitamina $C$ durante 112 dias $^{1}$

Table 4 - Mean values of erythrocytes (Erit), hematocrit (Htc), hemoglobin (Hb), mean corpuscular volume (MCV) and mean corpuscular hemoglobin concentration (MCHC) of Nile tilapia juveniles fed diets supplemented with different levels of vitamin $\mathrm{C}$ and lipids during 112 days

\begin{tabular}{|c|c|c|c|c|c|c|}
\hline Vit C (mg/kg) & Lip (\%) & Erit $\left(10^{6} / \mathrm{L}\right)$ & Htc $(\%)$ & $\mathrm{Hb}(\mathrm{g} / \mathrm{dL})$ & $\begin{array}{l}\mathrm{VCM}^{2}(\mathrm{fL}) \\
M C V\end{array}$ & $\begin{array}{c}\mathrm{CHCM}^{3}(\%) \\
\text { MCHC }\end{array}$ \\
\hline 0 & 0 & $1,67( \pm 0,17)$ & $27,10( \pm 1,20)$ & $7,75( \pm 0,75)$ & $163,25( \pm 15,06)$ & $28,30( \pm 2,69)$ \\
\hline 125 & 6 & $1,92( \pm 0,11)$ & $29,40( \pm 0,92)$ & $8,33( \pm 0,58)$ & $153,93( \pm 7,30)$ & $29,09( \pm 1,26)$ \\
\hline 300 & & $1,94( \pm 0,14)$ & $28,26( \pm 0,17)$ & $8,17( \pm 0,56)$ & $145,67( \pm 9,15)$ & $28,91( \pm 2,02)$ \\
\hline 600 & 8 & $2,09( \pm 0,20)$ & $29,20( \pm 1,29)$ & $7,65( \pm 0,33)$ & $139,71( \pm 13,16)$ & $26,20( \pm 1,62)$ \\
\hline 1.200 & & $1,99( \pm 0,10)$ & $30,27( \pm 2,01)$ & $7,96( \pm 0,34)$ & $152,11( \pm 13,78)$ & $26,30( \pm 2,27)$ \\
\hline 600 & 12 & $1,98( \pm 0,17)$ & $29,00( \pm 1,07)$ & $8,00( \pm 0,49)$ & $146,46( \pm 7,28)$ & $27,59( \pm 2,81)$ \\
\hline 1.200 & & $1,97( \pm 0,17)$ & $29,17( \pm 1,83)$ & $8,01( \pm 0,41)$ & $162,82( \pm 15,75)$ & $27,18( \pm 1,55)$ \\
\hline $\begin{array}{l}\text { Cont. } 1 \times \text { Fatorial }^{4} \\
\text { Control } 1 \times \text { Factorial }^{4}\end{array}$ & & 0,01 & 0,05 & ns & ns & ns \\
\hline $\begin{array}{l}\text { Cont. } 2 \times \text { Fatorial }^{5} \\
\text { Control } 2 \times \text { Factorial }^{2}\end{array}$ & & ns & ns & ns & ns & ns \\
\hline 600 & & 2,04 & 29,10 & 7,83 & 141,47 & 26,90 \\
\hline 1.200 & & 1,98 & 29,72 & 7,99 & 157,47 & 26,74 \\
\hline & $\operatorname{Lip}^{7}$ & ns & ns & ns & ns & ns \\
\hline & 8 & 2,01 & 29,24 & 7,92 & 145,83 & 27,14 \\
\hline & 12 & 1,98 & 29,22 & 8,08 & 152,76 & 27,54 \\
\hline Vit. $\mathrm{C} \times \mathrm{Lip}^{8}$ & & ns & ns & ns & ns & ns \\
\hline \multicolumn{7}{|c|}{$\begin{array}{l}1 \text { Letras minúsculas comparam os níveis de vit. C dentro de um mesmo nível de lipídeo (Small letters compare vit. Clevels within the same lipid level). Letras maiúsculas } \\
\text { comparam diferentes níveis de lipídeo dentro de um mesmo nível de vit. C (Capital letters compare different lipid levels within the same vit. C level). Médias seguidas } \\
\text { de letras iguais, ou sem letra, não diferem (Means followed by the same letter or absent did not differ). } \\
2 \text { Controle } 1 \text { (control 1) (ausente de suplementação de vitamina C e lipídeo) (No vitamin C and lipid supplementation) vs Fatorial, nível P (factorial, P level). } \\
3 \text { Controle } 2 \text { (control 2) ( } 125,0 \mathrm{mg} / \mathrm{kg} \text { vit. C e } 6,0 \% \text { lipídeo) (125 mg/kg vit. C) vs Fatorial, nível P (factorial, P level). } \\
4 \text { Efeito da vit. C, nível P (vit. C effect, P level). } \\
5 \text { Efeito do lipídeo, nível P (lipid effect, P level). } \\
6 \text { Interação vit. C } \times \text { lipídeo, nível P (vit. C } \times \text { lipid interaction, P level). }\end{array}$} \\
\hline
\end{tabular}

influencia apenas os parâmetros produtivos, mas também a reserva necessária para promover sua utilização normal pelo organismo e seu aporte para outros tecidos quando em situações adversas.

Assim como observado neste estudo, Hilton et al. (1978) afirmaram que a concentração de vitamina C no fígado dos peixes é influenciada, diretamente, pela concentração na dieta. Neste estudo, os peixes alimentados com as dietas com elevadas concentrações de vitamina C apresentaram altas concentrações dessa vitamina nos tecidos, o que representa aumento da proteção contra estresse e infecções (Lim et al., 2001; Norrgren et al., 2001; Ai et al., 2006).

Igualmente, Nitzan et al. (1996), estudando o efeito da suplementação de ácido ascórbico polifosfatado (AAPP) em rações para híbridos de tilápia (Oreochromis niloticus $\times$ Oreochromis aurus), determinaram concentração no fígado significativamente maior nos peixes que receberam suplementação de vitamina $\mathrm{C}$ em relação àqueles alimentados com as dietas sem suplementação. Em concordância, observou-se nesta pesquisa efeito significativo dos níveis de vitamina $\mathrm{C}$ na dieta sobre a quantidade de reserva desta vitamina no fígado (Tabela 3), uma vez que o acréscimo na dieta determinou aumento de sua concentração neste órgão. Observou-se ainda que a suplementação com 600 mg de vitamina C não diferiu da suplementação de $1.200 \mathrm{mg}$ vitamina $\mathrm{C} / \mathrm{kg}$ da dieta em relação à reserva. Assim, pode-se inferir que houve saturação do fígado quanto à sua capacidade de reserva e que, em termos econômicos, a melhor reserva ocorreu com $600 \mathrm{mg} / \mathrm{kg}$ da dieta.

A importância da suplementação dessa vitamina em níveis superiores ao recomendado para evitar sinais de deficiência e, conseqüentemente, determinar maior reserva foi afirmada por Navarre \& Halver (1989), que enfatizaram que peixes com alta concentração de ácido ascórbico nos tecidos apresentam maior tolerância à poluição ambiental e 
resistência a infecções por bactérias. Igualmente, Li \& Robinson (1994) avaliaram níveis de suplementação de vitamina $\mathrm{C}$ a diferentes temperaturas e observaram redução significativa na concentração desta vitamina no fígado $(44,0 \%)$ quando os peixes estavam sob situação de estresse, semelhante à passagem do verão para o inverno. Ressaltaram, portanto, a importância de se manter alta a reserva dessa vitamina em períodos que antecedem a redução de temperatura. Dietas suplementadas com elevados níveis dessa vitamina podem ter efeito benéfico não só na prevenção de doenças em peixes como também no aumento da resistência a infeç̧ões em peixes imunocomprometidos (Pezzato et al., 2004; Lim et al., 2005).

Comprovando os resultados inferiores obtidos no desempenho produtivo, nos parâmetros hematológicos e na concentração de vitamina $C$ no fígado dos peixes alimen- tados com a dieta sem suplementação em relação à média do fatorial, observou-se porcentagem inferior de colágeno nas vértebras dos peixes alimentados com esta dieta em relação àqueles sob suplementação (Figura 1). Do mesmo modo, notou-se formação irregular das vértebras dos peixes alimentados com essa dieta, como conseqüência da baixa porcentagem de colágeno, o que sugere início de lordose e escoliose.

A quantidade de colágeno nas vértebras de muitas espécies de peixes tem sido utilizada como indicador subclínico de deficiência de vitamina C (Mustin \& Lovell, 1992). Porcentagem igual ou inferior a $25,0 \%$ de colágeno na vértebra de bagre-do-canal é considerada sinal de deficiência de vitamina $\mathrm{C}$, uma vez que a diminuição desta porcentagem nas vértebras aparece anteriormente à ocorrência de sinais clínicos de deficiência como: lordose, escoliose e/ou

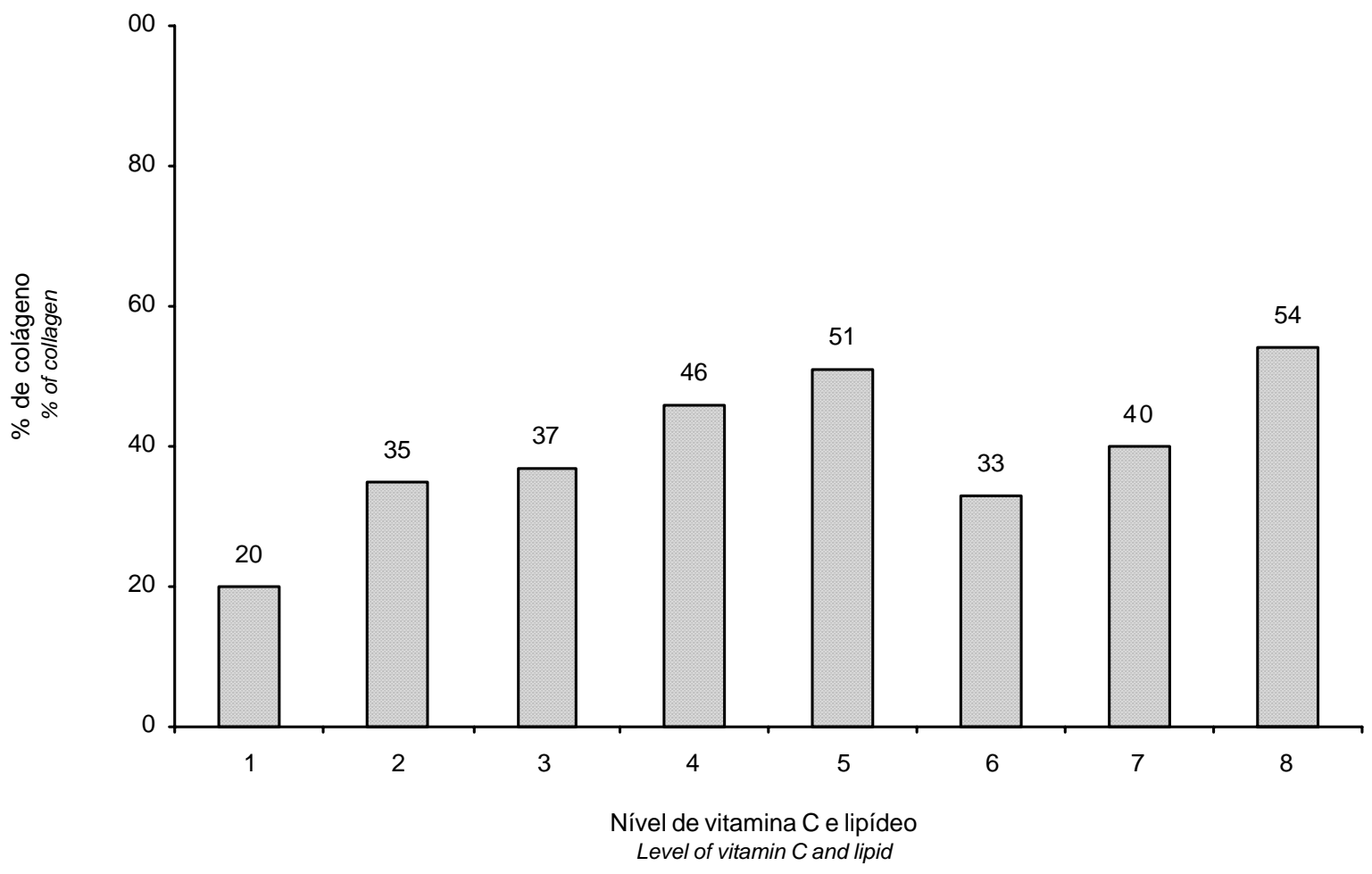

Figura 1 - Porcentagem média de colágeno nas vértebras de alevinos de tilápia-do-nilo alimentado durante 112 dias com dietas suplementadas com vitamina C e lipídeo.

Figure 1 - Mean percentage of vertebrae collagen of Nile tilapia juveniles fed diets supplemented with different levels of vit. $C$ and lipids during 112 days. 1 - 0 mg vit. C/0\% lip; 2 - 125 mg vit. C/6\% lip; 3 - 300 mg vit. C/8\% lip; $4-600$ mg vit. C/8\% lip; 5 - $1.200 \mathrm{mg}$ vit. C/8\% lip; 6 - 300 mg vit. C/12\% lip; 7 - 600 mg vit. C/12\% lip; $8-1.200$ mg vit. C/12\% lip.

escorbuto (Li \& Robinson, 2001). Igualmente, Ai et al. (2006) relataram baixa concentração de colágeno nas vértebras de Pseudosciaena crocea alimentados com dieta sem suplementação de vitamina $\mathrm{C}$ em relação àqueles alimentados com dietas suplementadas.

\section{Conclusões}

A energia adicional proveniente do lipídeo é depositada na cavidade abdominal em forma de gordura visceral. A deposição desta gordura como reserva de energia para 
maior resistência no período de inverno foi obtida em todos os níveis de suplementação de lipídeo; a suplementação com 8,0\% foi a mais adequada; a concentração de vitamina C no fígado é proporcional à concentração na dieta, porém, em virtude da capacidade de reserva desse órgão, a quantidade de $600 \mathrm{mg}$ de vitamina $\mathrm{C} / \mathrm{kg}$ da dieta mostrou-se economicamente adequada e a ausência de vitamina C prejudicou a eritropoiese e a síntese de colágeno.

\section{Agradecimento}

À Fundação de Amparo à Pesquisa do Estado de São Paulo, FAPESP, pela bolsa de estudo concedida; e à Socil Guyomarc’h Indústria e Comércio Ltda, pelo apoio científico.

\section{Literatura Citada}

ADHAM, K.G.; HASHEM, H.O.; ABU-SHABANA, M.B. et al. Vitamin $C$ deficiency in the catfish Clarias gariepinus. Aquaculture Nutrition, v.6, p.129-139, 2000.

AI, Q.; MAI, K.; TAN, B. et al. Effects of dietary vitamin C on survival, growth, and immunity of large yellow croaker, Pseudosciaena crocea. Aquaculture, n.261, p.327-336, 2006.

ALBREKTSEN, S.; LIE, O.; SANDERS, K. Ascorbyl palmitate as a dietary vitamin $\mathrm{C}$ source for rainbow trout (Salmo gairdneri). Aquaculture, v.71, p.359-365, 1988.

ANDREWS, J.W.; MURAI, T. Studies of the vitamin C requirements of channel catfish (Ictalurus punctatus). Journal of Nutrition, v.105, p.557-561, 1975.

ASSOCIATION OF OFFICIAL ANALYTICAL CHEMISTS - AOAC. Official methods of analysis. 17.ed. Washigton, D.C.: 2000. 1094p.

BALFRY, S.K.; HIGGS, D.A. Influence of dietary lipid composition on the immune system and disease resistance of finfish. In: LIM, C.; WEBSTER, C.D. (Eds.) Nutrition and fish health. New York: Haworth Press, 2001. p.213-225.

BARROS, M.M.; PEZZATO, L.; KLEEMANN, G.K. Níveis de vitamina C e ferro para tilápia do Nilo (Oreochromis niloticus). Revista Brasileira de Zootecnia, v.31, p.2149-2159, 2002.

BEAMISH, F.H.; MEDLAND, T.E. Protein sparing effects in large rainbow trout, Salmo gairdneri. Aquaculture, v.55, p.35-42, 1986.

BOYD, C.E. Water quality management for ponds fish culture. Development in aquaculture and fisheries science. New York: Elsevier Scientific Publishing Company, 1990. 315p.

CHAGAS, E.C.; VAL, A.L. Efeito da vitamina C no ganho de peso e em parâmetros hematológicos de tambaqui. Pesquisa Agropecuária Brasileira, v.38, n.3, p.397-402, 2003.

CHEN, R.; LOCHMANN, R.; GOODWIN, A. et al. Alternative complement activity and resistance to heat stress in golden shiners Notemigonus Crysoleucas are increased by dietary vitamin $C$ levels in excess of requirements for prevention of deficiency signs. Journal of Nutrition, v.133, p.2281-2286, 2003.

CHEN, R.; LOCHMANN, R.; GOODWIN, A. et al. Effects of dietary vitamins $\mathrm{C}$ and $\mathrm{E}$ on alternative complement activity, hematology, tissue composition, vitamin concentrations and response to heat stress in juvenile golden shiner (Notemigonus crysoleucas). Aquaculture, v.242, p.553-569, 2004.

CHIEN, R.G.; HWANG, D.F. Effects of thermal stress and vitamin $\mathrm{C}$ on lipid peroxidation and fatty acid composition in the liver of thornfish Terapon jarbua. Comparative Biochemistry Physiology, v.128, p.91-97, 2001.
CHOU, B.S.; SHIAU, S.Y. Optimal dietary lipid level for growth of juvenile hybrid tilapia, Oreochromis niloticus $x$ Oreochromis aureus. Aquaculture, v.143, p.185-195, 1996.

DE SILVA, S.S.; GUNASEKERA, R.M.; SHIM, K.F. Interactions of varying dietary protein and lipid levels in young red tilapia: evidence of protein sparing. Aquaculture, v.95, p.305-18, 1991.

FITZSIMMONS, K.; DICKENSON, G.; BRAND, C. et al. Effects of reducing dietary lipid levels on growth and body composition of hybrid tilapia in an intensive recirculating-water system. The Progressive Fish Culurist, v.59, p.293-296, 1997.

HANLEY, F. Effects of feeding supplementary diets containing varying levels of lipid on growth, food conversion, and body composition of Nile tilapia Oreochromis niloticus (L.) Aquaculture, v.93, p.323-334, 1991.

HAYASHI, C.; MEURER, F.; SOARES, C.M. et al. Utilização de diferentes níveis de gordura em dietas para alevinos de carpacapim (Ctenonpharyngodon idella, V). In: CONGRESSO BRASILEIRO DE ENGENHARIA DE PESCA, 11., 1999, Olinda. Anais... Olinda: Congresso Brasileiro de Engenharia de Pesca: 1999b. p.201-210.

HILTON, J.W.; CHO, C.Y.; SLINGER, S.J. Effect of graded levels of supplemental ascorbic acid in practical diets of rainbow trout. Journal of the Fisheries Research Board Canada, v.35, p.431-436, 1978.

JAIN, N.C. Schalm's veterinary hematology. 4.ed. Philadelphia: Lea \& Febiger, 1986. 1344p.

JAUNCEY, K.; ROSS, B. A guide to tilapia feed and feeding. Scotland: Institute of Aquaculture, University of Sterling, 1982. 1087p.

LANNA, E.A.T.; PEZZATO, L.E.; FURUYA, W.M. et al. Fibra Bruta e Óleo em Dietas Práticas para Alevinos de Tilápia do Nilo (Oreochromis niloticus). Revista Brasileira de Zootecnia, v.33, n.6, p.2177-2185, 2004.

LEHNinger, A.L.; NELSON, D.L.; COX, M.M. Princípios de bioquímica. São Paulo: Savier, 1995. 1152p.

LEMLY, A.D. Wastewater discharges may be most hazardous to fish during winter. Environmental Pollution, v.32, p.169$174,1996$.

LI, M.H.; LOVELL, R.T. Elevated levels of dietary ascorbic acid increase immune responses in channel catfish. Journal of Nutrition, v.115, p.123-131, 1985.

LI, M.H.; ROBINSON, E.H. Dietary ascorbic acid requirement for growth and health in fish. In: LIM, C.; WEBSTER, C.D. (Eds.) Nutrition and fish health. New York: Haworth Press, 2001. p.163-175.

LI, M.H.; ROBINSON, E.H. Effect of dietary vitamin C on tissue vitamin $\mathrm{C}$ concentration in channel catfish, Ictalurus punctatus, and clearance rate at two temperatures - a preliminary investigation. Journal of Applied Aquaculture, v.4, p.5971, 1994.

LIM, C.; KLESIUS, P.H.; LI, M.H. et al. Interaction between dietary levels of iron and vitamin $\mathrm{C}$ on growth, hematology, immune response and resistance of channel catfish (Ictalurus punctatus) to Edwardsiella ictaluri challenge. Aquaculture, v.185, p.313$327,2000$.

LIM, C.; SHOEMAKER, C.A.; KLESIUS, P.H. The effect of ascorbic acido $\mathrm{n}$ the immune response in fish. In: DABROWSKI, K. (Ed.) Ascorbic acid in aquatic organisms. Boca Raton: CRC Press, 2001. p.149-166.

LIM, C; YILDIRIM-AKSOY, M.; KLESIUS, P.H. Nutrition, immune response and disease resistance in fish. In: SIMPÓSIO DE NUTRIÇÃO E SAÚDE DE PEIXES, 1., 2005, Botucatu. Anais... Botucatu, 2005. p.46-83.

LOVELL, R.T. Nutrition and feeding of fish. 2.ed. Massachusetts: Academic Press, 1998. 267p.

LOVELL, R.T.; SIRIKUL, B. Winter feeding of channel catfish. Procedings Annual Conference Southeast Association Game Fish Community, v.28, p.208-216, 1974.

MEURER, F.; HAYASHI, C.; BOSCOLO, W.R. et al. Lipídeos na alimentação de alevinos revertidos de tilápia do Nilo 
(Oreochromis niloticus, L.). Revista Brasileira de Zootecnia, v.31, p.566-573, 2002.

MUSTIN, W.G.; LOVELL, R.T. Na-L-ascorbyl-2-monophosphate as a source of vitamin $C$ for channel catfish. Aquaculture, v.105, p.95-100, 1992.

NAVARRE, O.; HALVER, J.E. Disease resistance and humoral antibody production in rainbow trout fed high levels of vitamin C. Aquaculture, v.79, p.207-221, 1989.

NITZAN, S.; ANGEONI, H.; GUR, N. Effects of ascorbic acid polyphosphate (AAPP) enrichment on growth, survival and disease resistanse of hybrid tilapia. Israeli Journal of Aquaculure, v.48, p.133-141, 1996.

NORRGREN L.; BORJESON, H.; FORLIN, L. et al. The role of ascorbic acid and its derivatives in resistance to environmental and dietary toxicity of aquatic organisms. In: DABROWSKI, K. (Ed.) Ascorbic acid in aquatic organisms. Boca Raton: CRC Press, 2001. p.167-189.

PANDIAN, T.J.; RAGHURAMAN, R. Effects of feeding rate on conversion efficiency and chemical composition of the fish Tilapia mossambica. Marine Biology, v.1, p.16-32, 1972.

PEZZATO, L.E.; BARROS, M.M.; FRACALOSSI, D.M. et al. Nutrição de peixes. In: CYRINO, J.E.P.; URBINATI, E.C.; FRACALOSSI, D.M. et al. (Eds.) Tópicos especiais em piscicultura de água doce tropical intensiva. São Paulo: TecArt, 2004. p.74-169.

PEZZATO, L.E.; MIRANDA, E.C.; BARROS, M.M. et al. Digestibilidade aparente de ingredientes pela tilápia do Nilo (Oreochromis niloticus). Revista Brasileira de Zootecnia, v.31, p.1595-1604, 2002.

RASMUSSEN, R.S. Quality of farmed salmonids with emphasis on proximate composition, yield and sensory characteristics. Aquaculture Research, v.32, p.767-786, 2001.

SATO, M.R.; YOSHINAKA, R.; YAMAMOTO, S. Nonessestiality of ascorbic acid in the diet of carp. Bulletin Japanese Society Science Fisheries, v.44, p.1151-1156, 1978.

SHIAU, S.Y.; JAN, F.L. Dietary ascorbic acid requirement of juvenile tilapia Oreochromis niloticus $x$ O. aureus. Fisheries Science, v.58, p. 671-675, 1992.
SOBHANA, K.S.; MOHAN, C.V.; SHANKAR, K.M. Effect of dietary vitamin $\mathrm{C}$ on the disease susceptibility and inflamamatory response of mrigal, Cirrhinus mrigala (Hamilton) to experimental infection of Aeromonas hydrophila. Aquaculture, v.207, p.225-238, 2002.

STICKNEY, R.R. Tilapia nutrition, feeds and feeding. In: COSTAPIERCE, B.A.; RAKOCY, J.E. (Eds.) Tilapia aquaculture in the Americas. Luisiana: World Aquaculture Society, 1997. p.34-54.

Van der MEER, M.B.; ZAMORA, J.E.; VERDEGEM, M.C.J. Effect of dietary lipid level on protein utilization and the size and proximate composition of body compartments of Colossoma macropomum. Aquaculture Research, v.28, p.405-417, 1997.

VIOLA, S.; AMIDAN, G. Observations on the accumulation of fat in carp and Sarotherodon (Tilapia) fed oil-coated pellets. Bamidgeh, v.32, p.33-40, 1980.

WANG, X.Y.; MING-LONG, L.; HUNG, T.H. et al. Liquid chromatographic determination of L-ascorbate 2-polyphosphate in fish feeds by enzymatic release of L-ascorbate. Journal Association Official Analytical Chemistry, v.71, p.11581161, 1988.

WEDEMEYER, G. Stress induced ascorbic acid depletion and cortisol production in two salmonid fish. Comparative Biochemistry Physiology, v.29, p.1247-1251, 1969.

YASSIN, N. Análise de experimentos fatoriais de dois fatores com tratamentos adicionais. Lavras: Universidade Federal de Lavras, 2001. 118p. Dissertação (Mestrado em Zootecnia) Universidade Federal de Lavras, 2001.
Recebido: 6/10/2006 Aprovado: 11/4/2007 